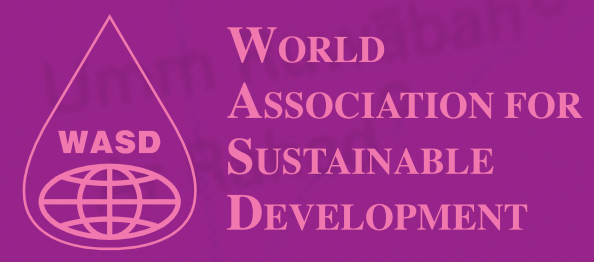

\author{
Soheir N. Abd El-Rahman ${ }^{1}$ \\ Agriculture Research Center, Egypt \\ and \\ Suhailah S. Al-Jameel² \\ University of Dammam, Saudi Arabia
}

\title{
Efficacy of nano curcumin in F-2 isoprostanes in male rats treated with Cisplatin and Methotrexate as chemotherapy drugs
}

1 Prof. Soheir N. Abd El. Rahman (Corresponding author), Crops Technology Research Department, Food Technology Research Institute, Agriculture Research Center, Giza, Egypt, Email: soheirkenawy@Yahoo.com 2 Suhailah S. Al-Jameel, College of Science, University of Dammam, Dammam Kingdom of Saudi Arabia, Email: ssaljameel@ud.edu.sa 
Efficacy of nano curcumin in F-2 isoprostanes in male rats treated with Cisplatin and Methotrexate as chemotherapy drugs 


\section{Abstract}

Purpose This work is based on nanoparticipation technique for preparation of curcumin nanoparticles (CURNPs) and study the effect of CURNPs (30,60 mg/kg b.w) as antioxidants on the nephrotoxicity induced by cisplatin (CDDP) $(6 \mathrm{mg} / \mathrm{kg}$ b.w i.p) and methotrexate (MTX) (20 $\mathrm{mg} / \mathrm{kg}$ b.w i.p).

Methodology Physicochemical characterization of CURNPs was studied by Zetasizer Nano ZS, TEM and BET surface area. Urea, creatinine, SOD, CAT and F-2Isoprostanes (F-2 isoPs) in serum were estimated. Also, morphological changes of kidney were studied.

Findings The results indicated that the CDDP and MTX induced increase of urea, creatinine and F-2IsoPs concentrations and decline of serum antioxidant enzymes (SOD and CAT) activities. On the other hand, urea, creatinine and F-2IsoPs, were reduced and (SOD and CAT) activities were increased significantly $(p<0.05)$ in the CURNPs (30,60 mg/kg b.w) + CDDP/ MTX treated groups. Moreover, CURNPs (30,60 mg/kg b.w) + CDDP/ MTX treated groups resulted in a marked of morphological protection against the drugs induced nephrotoxicity and confirmed the pathological improvement in the kidney tissue.

Originality/value This study concluded that CURNPs has a strong potential to be used as a strong antioxidant in CDDP and MTX nephrotoxicity. Most importantly, CURNPs (60 mg/kg b.w) was much more effective and better nephroprotective agent than CURNPs (30 mg/kg b.w). These findings provide further understanding for the possible therapeutic effects of CURNPs in further pre-clinical and clinical research.

Keywords Curcumin nanoparticles (CURNPs), F-2isoprostans (F-2isoPs), Cisplatin (CDDP), Methotrexate (MTX), Nephrotoxicity. 


\section{Introduction}

Chemotherapeutic agents are large, broad class of pharmaceutical agents used to fight cancers and other disease. Chemotherapy induced apoptosis generally results in ROS/RNS generation (Kannan and Jain 2000). Fabbro et al, (2006) said that Generation of ROS/ RNS gives rise to drug-induced toxicity as a result of damage to healthy tissue. The CDDP and MTX are employed for the treatment of solid tumors, deserves investigation because toxicity has been assigned to each of the drugs. MTX is an antimetabolite and antifolate drug used widely as a cytotoxic chemotherapeutic agent for treatment of leukemia (Jahovic et al., 2003), many kinds of cancer, rheumatoid arthritis, psoriasis, immunological abnormalities and systemic inflammation has been widely used (Koyama et al., 2003; Turesson and Matteson 2006). On the other hand, MTX treatment is associated with a number of adverse reactions, including, pneumonitis, nephrotoxicity and hepatotoxicity (HSU et al., 2003). Nephrotoxicity is an adverse effect of MTX, more than $90 \%$ of MTX is cleared by the kidneys (Izzedine et al., 2005). MTX treatment at high doses and in increased lipid peroxidation in the kidney as revealed by elevated malondialdehyde (MDA) may cause renal failure (Abelson et al., 1983). Reactive oxygen species (ROS) are implicated in the pathogenesis of MTX-induced renal damage (Devrim et al., 2005; Öktem et al., 2006; Abraham et al., 2010).

\section{Pabla and Dong (2008) reported that} CDDP (cis-diamminedichloro platinum II) is a chemotherapeutic agent that is used for the treatment of a wide variety of cancers, but nephrotoxicity is a major dose-limiting side-effect (Yao et al., 2007). It has been reported to enhance, superoxide anions (O2.-) (Davis et al., 2001), peroxynitrite anions (Srivastava et al., 1996), hydrogen peroxide (H2O2) (Baek et al., 2003), and hydroxyl radicals $(\mathrm{OH}$.$) via mobi-$ lization of iron from renal cortical mitochondria (Baliga et al., 1997; Durak et al., 2002). Thus, CDDP-induced nephrotoxicity is closely associated with an increase in lipid peroxidation in the kidney tissues (Sugihara and Gemba 1986; Hannemann and Baumann 1988; Sadzuka et al., 1992). Moreover, CDDP induced glutathione depletion is a determinant step in oxidative stress in kidney tissue that leads to nephrotoxicity (Jin-Gang and Lindup 1993). Also, Weijl et al, (1998) suggested that CDDP chemotherapy induces a fall in plasma antioxidant levels, which may reflect a failure of the antioxidant defense mechanism against oxidative damage induced by commonly used antitumor drugs.

Curcumin (CUR) is a dietary antioxidant derived from turmeric (Curcuma longa, Zingiberaceae) and has been known since ancient times to possess therapeutic properties. It is able to scavenge O2 $\square$. (Tuba et al., 2008; Sreejayan and Rao 1997), OH·, H2O2 (Tuba et al., 2008), singlet oxygen (Das and Das 2002), nitric oxide (Kim et al., 2003) and peroxynitrite (Cohly et al., 1998). Phenolic groups in the structure of CUR (Fig.1) explains its ability to react with ROS and RNS and might probably be one of the mechanisms through which CUR treatment protects the epithelial cells of renal tubules (LLC-PK1) from oxidative damage induced by $\mathrm{H} 2 \mathrm{O} 2$ (Cohly et al., 1998). The indirect antioxidant capacity of CUR is defined by 
its ability to induce the expression of cytoprotective proteins such as superoxide dismutase (SOD) and catalase (CAT) (Panchal et al., 2008).

F2-IsoPs are stable prostaglandin-like compounds formed from the peroxidation of arachidonic acid and present in detectable quantities in normal biological tissues and fluids, are unaffected by lipid content of the diet (Robertsand Jason, 2000). As F2-IsoPs levels are modulated by antioxidant status they are ideal markers of oxidative stress (Fam and Morrow 2003; Grosso et al., 2011; Il'Yasova et al., 2011). Also, F2-IsoPs levels have been shown to increase substantially in animal models of oxidant injury. The ability to quantify F2-IsoPs has allowed exploration of the role free radicals play in the pathophysiology of numerous human diseases (Robertsand Jason, 2000; Fam and Morrow 2003; Grosso et al., 2011; Ye et al., 2007). Il'Yasova et al, (2010) studied urinary F2-IsoPs in 23 breast cancer patients receiving doxorubicin and they found, the clinical model of oxidative assault revealed that F2IsoPs is a reliable biomarker for monitoring oxidative status during chemotherapy treatment. Protas et al, (2010) found elevated F2-IsoPs in 38 children receiving chemotherapy for leukemia, suggesting that neurotoxicity during treatment may be related to oxidative stress.

However, we weren't able to find any study evaluating F2-IsoPs concentrations in nanocurcumin with chemotherapy induced nephrotoxicity. The main objective of this study was to describe biochemical changes in oxidative stress, measured by the biomarkers F2-IsoPs, SOD, CAT and renal functions tests (urea and creatinine) concentrations in serum of male rats undergoing CDDP and MTX drugs as a marker of chemotherapy-induced oxidative stress. It also considered to study histopathological of kidney tissue undergoing chemotherapy.

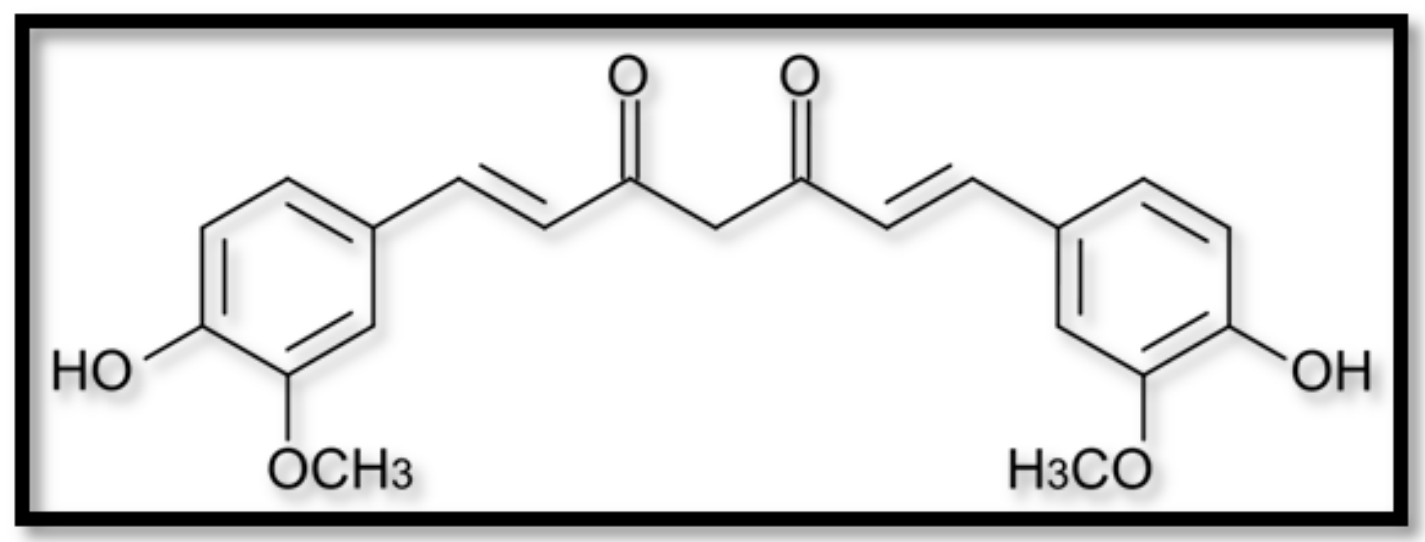




\section{Materials and Methods}

\section{Materials}

Poly ( $D$, L-lactic-co-glycolic acid) (PLGA) (Resomer R503H; MW 35-40 kDa), poly (vinyl alcohol) (PVA) (MW 30-70 kDa), High-performance liquid chromatography-grade ethanol, and distilled water were procured from J.T. Baker (now Avantor Performance materials, Phillipsburg, NJ). Cisplatin, Methotrexate and curcumin were purchased from Sigma-Aldrich (Poole, UK).

\section{Methods}

Preparation of curcumin nanoparticles The homogeneous solution was obtained during dissolve commercial CUR (7.5 mg) and PLGA (50 mg) in $2.5 \mathrm{ml}$ of ethyl acetate and stirred at 1,000 rpm for 30 min at room temperature. PVA (50 mg), used as a stabilizer, was dissolved in $5 \mathrm{ml}$ distilled water (Devadasu et al., 2011).

\section{Characterization of curcumin nanoparticles}

Particle size was determined by dynamic light scattering (DLS) using Zetasizer Nano ZS (Malvern InstrumentsLtd., Malvern, UK).

Nanoparticles were characterized for size and morphology using an JEOL1210 transmission electron microscope (TEM) (JEOL, Tokyo, Japan) operating at $60 \mathrm{kV}$.

The specific surface area per mass unit $(\mathrm{m} 2 \mathrm{~g}-1)$ was determined by means of Brunauer, Emmet and Teller (BET) analysis (adsorption of nitrogen in cryogenic condition) using a Micromeritics Gemini $\vee$ instrument.

\section{Biological methods}

Male adult rats (54 animals weighing 200-250g) were obtained from the animal house in University of Dammam. Rats were housed in individual cages with screen bottoms and fed on basal diet (corn starch $70 \%$, casein $10 \%$, corn seed oil $10 \%$, cellulose $5 \%$, salt mixture $4 \%$ and vitamins mixture $1 \%$ ) for ten days. Rats were kept under standard conditions of temperature $\left(21 \pm 0.5^{\circ}\right)$ and relative humidity (55 \pm 5 ) with $12 \mathrm{~h}$ light/12h dark cycle. After equilibration, rats were weighted and divided into 9 groups (six animals per each) everyone was assigned to one of the eleven diet groups. Group 1 used as control ( $2 \mathrm{ml}$ saline orally) once daily for five consecutive days, Group 2 was received CURNPs $(60 \mathrm{mg} / \mathrm{kg}$ b.w orally) once daily for five consecutive days, Group 3 was treated with single dose of CDDP (6 mg/ kg b.w) i.p injection + CURNPs (60 mg/ kg b.w orally) daily for five consecutive days, Group 4 was treated with single dose of MTX (20 mg/ kg b.w) i.p injection + CURNPs (60 mg/ kg b.w orally) daily for five consecutive days, Group 5 received CURNPs (30 mg/ kg b.w orally) once daily for five consecutive days, Group 6 was treated with single dose of CDDP $(6 \mathrm{mg} / \mathrm{kg}$ b.w) i.p injection + CURNPs (30 mg/ kg b.w orally) daily for five consecutive days, Group 7 was treated with single dose of MTX $(20 \mathrm{mg} / \mathrm{kg}$ b.w) i.p injection + CURNPs (30 mg/ $\mathrm{kg}$ b.w orally) daily for five consecutive days, Group 8 was injected intraperitoneally (i.p) with single dose of CDDP (6 mg/ kg b.w), Group 9 was injected intraperitoneally with single dose of MTX (20 mg/ kg b.w). On the sixth day, the animals of each group were killed by decapitation. Blood samples were collected from the orbital plexus by mean of heparinized capillary glass tubes. Each sample was placed into a dry clean centrifuge tube and centrifuged $1500 \mathrm{xg}$ for $30 \mathrm{~min}$. at $4^{\circ} \mathrm{C}$ to obtain serum. 


\section{Biochemical assays}

\section{Urea and Creatinine assays}

Serum urea was determined according to Fawcett and Soctt (1960) and creatinine was determined according to the method of Barthesand Bohemer, (1972).

\section{Superoxide dismutase (SOD) and Catalase (CAT) assay}

The enzymatic activity of SOD was measured as described by Ohkuma et al, (1982) and CAT activity was assayed by the method of Luck (1963). F2-Isoprostanes (F2-IsoPs) assay F2-IsoPs were measured using a competitive enzyme-linked immunoassay (ELISA) kit according to instructions (Cayman Chemical, Ann Arbor, MI) (Morrow and Roberts 1997).

\section{Histopathological Examination}

For microscopic evaluation, kidneys were fixed in $10 \%$ neutral phosphate buffered formalin solution. Following dehydration in an ascending series of ethanol $(70,80,96,100 \%)$, tissue samples were cleared in xylene and embedded in paraffin. Tissue sections of $5 \mu \mathrm{m}$ were stained with hematoxylin-eosin (H-E). A minimum of 10 fields for each kidney slide were examined and assigned for severity of changes by an observer blinded to the treatments of the animals. Statistical Analysis Results were expressed as mean SEM. The intergroup variation was measured by one way analysis of variance (ANOVA) followed by Fischer's LSD test. Statistical significance was considered at $(P<0.05)$. The statistical analysis was done using the Jandel Sigma Stat Statistical Software version 2.0.

\section{Results and Discussion}

\section{Characterization of CURNPs}

The particle size analysis was performed by DLS (Fig. 2). DLS of the aqueous dispersion of CURNPs revealed the formation of nanoparticles with an average hydrodynamic diameter of $102.3 \mathrm{~nm}$. Using Homogenization for (30 minutes) on (25000 rpm) may had a big role in getting the size of a nano small particle, $102.3 \mathrm{~nm}$ as indicated by measurements of Zeta in the form of fig 2, which was obtained successfully small particle size compared to the size $(237 \pm 6)$ indicated by the study of Devadasu et al, (2011). This can be explained as a result of high energy resulting from the Homogenization process, which affect the converted from micro scale to nano scale. Also, increase the time required for this process and increase the number of courses has led to increase the rate of forming particles and thus to obtain nanoparticles much smaller (Feczkó et al., 2008; Shi et al., 2011). The morphological examination of CURNPs was performed using a TEM (Fig. 3). It showed that the most of CURNPs have a good smooth spherical shape with a uniform size distribution, and the particle size was in the range of (2-100 $\mathrm{nm}$ ). The particles are characterized as being uniform somewhat in terms of size and shape. This is due to the use of the homogenization process, which plays an important role in the emergence of symmetric molecules form. The surface area of original CUR and CURNPs were performed by BET. Original CUR surface area was 55.43 $\mathrm{m} 2 / \mathrm{g}$. On the other hand, surface area of CURNPs was $667.79 \mathrm{~m} 2 / \mathrm{g}$. The increased in surface area of CURNPs might be due to the decreased in particle size of CURNPs. Similar findings were also observed by other studies (Shi et al., 2011; Wu et al., 2009). 
Figure 2. Size characterization of Curcumin nanoparticles

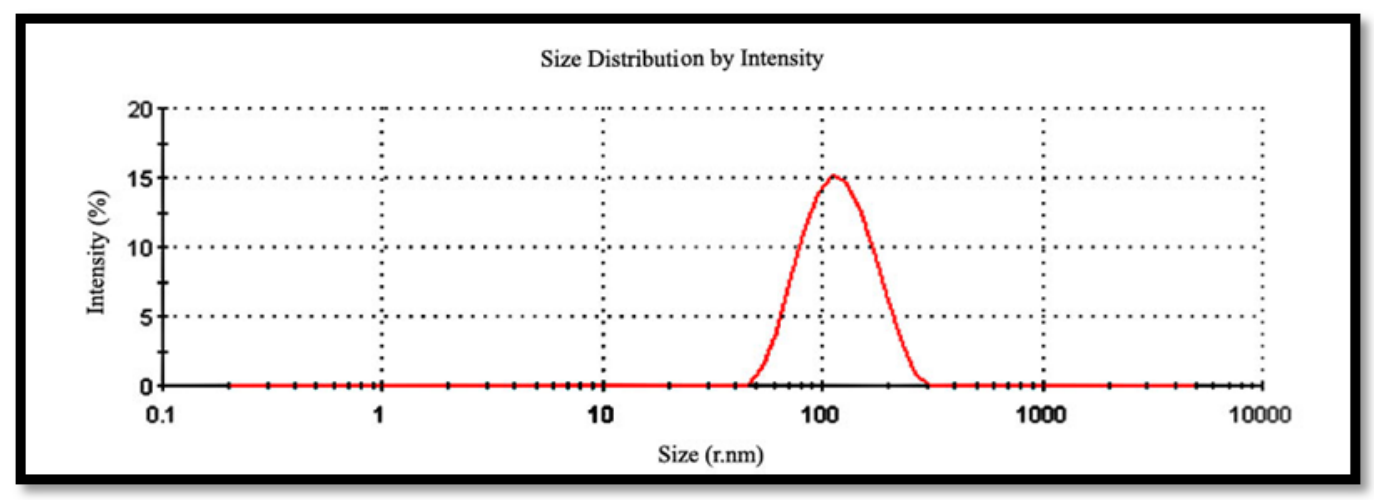

Figure 3. TEM image of Curcumin nanoparticles
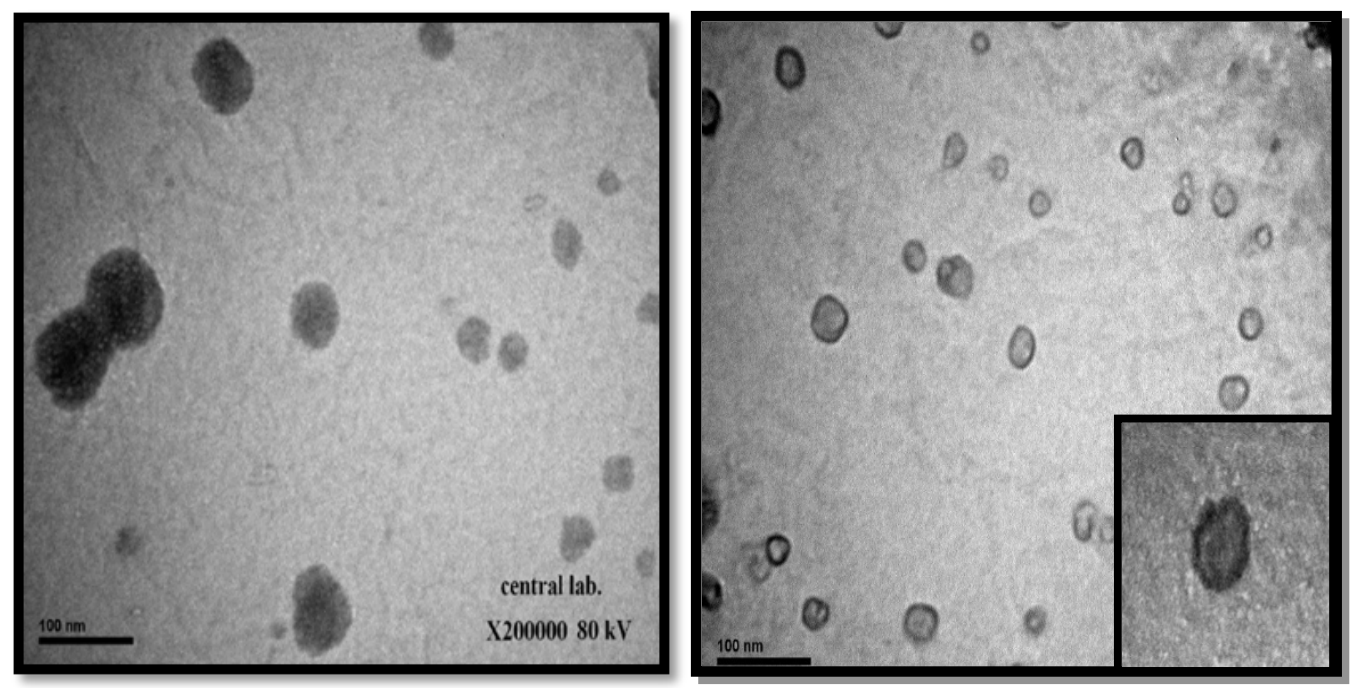

\section{Biological study}

\section{Effect of CURNPs on Urea and Creatinine}

Table 1 shows the effect of CURNPs on serum urea and creatinine. The concentrations of urea and creatinine were significantly increased $(p<0.05)$ in the CDDP ( $6 \mathrm{mg} / \mathrm{kg} \mathrm{b.w)}$ treated group (PC1) $(114.61 \mathrm{mg} / \mathrm{dl})$ and $(1.46 \mathrm{mg} /$ dl), respectively, compared to negative control (NC) $(24.44 \mathrm{mg} / \mathrm{dl})$ and $(0.74 \mathrm{mg} / \mathrm{dl})$, respectively. Serum urea and creatinine in groups treated with CURNPs $(60,30 \mathrm{mg} / \mathrm{kg}$ b.w $)+$ CDDP were reduced to $(38.24 \mathrm{mg} / \mathrm{dl}$ and $81.29 \mathrm{mg} / \mathrm{dl})$ in urea and $(0.74 \mathrm{mg} / \mathrm{dl}$ and $0.94 \mathrm{mg} / \mathrm{dl}$ ) in creatinine concen trations, respectively, with respect to the PC1.

The concentrations of urea and creatinine were significantly increased $(p<0.05)$ in the MTX $(20 \mathrm{mg} / \mathrm{kg} \mathrm{b.w})$ treated group (PC2) $(240.43 \mathrm{mg} / \mathrm{dl})$ and $(2.05 \mathrm{mg} / \mathrm{dl})$, respectively, compared to NC (24.44 mg/dl) and (0.74 $\mathrm{mg} / \mathrm{dl})$, respectively. On the other hand, serum urea and creatinine in groups treated with CURNPs (60, $30 \mathrm{mg} / \mathrm{kg}$ b.w) + MTX were decreased significantly $(p<0.05)$ compared to PC2. It observed $(31.07 \mathrm{mg} / \mathrm{dl}$ and $93.14 \mathrm{mg} / \mathrm{dl}$ ) in urea concentration and $(0.83 \mathrm{mg} / \mathrm{dl}, 1.01 \mathrm{mg} / \mathrm{dl})$ in creatinine concentration, respectively. 
Table 1. Effect of CURNPs (30,60mg/kg b.w) on serum Urea and Creatinine concentrations in male rats treated with Cisplatin (6 $\mathrm{mg} / \mathrm{kg} \mathrm{b.w}$ ) and Methotrexate (20 mg/kg b.w).

\begin{tabular}{|ccc|}
\hline Treatments & Urea $(\mathrm{mg} / \mathrm{dl})$ & Creatinine(mg/dI) \\
\hline Negative control NC & $0.50 \pm 24.44$ & $0.01 \pm 0.74$ \\
\hline CURNPs 60mg & $22.72 \pm 0.65$ & $0.71 \pm 0.01$ \\
\hline CURNPs 60mg + CDDP & $0.84 \pm 38.24$ & $0.01 \pm 0.74$ \\
\hline CURNPs 60mg + MTX & $31.70 \pm 1.31$ & $0.83 \pm 0.00$ \\
\hline CURNPs 30mg & $0.37 \pm 23.25$ & $0.00 \pm 0.75$ \\
\hline CURNPs 30mg + CDDP & $81.59 \pm 0.75$ & $0.94 \pm 0.01$ \\
\hline CURNPs 30mg + MTX & $0.50 \pm 93.14$ & $0.01 \pm 1.01$ \\
\hline MTX PC2 & $114.61 \pm 1.75$ & $1.46 \pm 0.02$ \\
\hline
\end{tabular}

Each value represents mean $\pm S D$ of six animals, CURNPS = curcumin nanoparticles, CDDP $(P C 1)=$ cisplatin (positive control 1), MTX (PC2) = Methotrexate (positive control 2), statistically significant at $P<0.05$ as compared to negative control (NC) (One-way ANOVA followed by Fischer's LSD test). 
Our results are corroborated by previous studies reported by other investigators on CDDP induced nephrotoxicity in normal rats (Kersten et al., 1998; Appenroth et al., 1997). It has been suggested that binding of CDDP to the renal base transport system and the following peroxidation of membrane lipids may account for its nephrotoxicity (Safirstein et al., 1984). It has been suggested that oxidative and nitrosative stresses are the two main cascades involved in CDDP induced nephrotoxicity (Baek et al., 2003). CDDP is known to generate ROS such as hydroxyl radicals, and stimulates renal lipid peroxidation (Sugihara et al., 1987). CDDP also, increased xanthine oxidase $(X O)$ activity in rat kidney tissue, which indicates excessive superoxide radical production and can cause oxidant stress and peroxidation in the cells, causing acute renal failure (Mcmanaman 2002). In the present study, a single dose of CDDP induced nephrotoxicity which was observed by biochemical parameters as a significant increase in serum creatinine. Several investigations have shown that CDDP nephrotoxicity is associated with lipid peroxidation in radical-mediated chain reaction that damages cell membranes, and the inhibition of this process by CUR is mainly attributed to the ability of scavenger free radicals (Sreejayan et al., 1997).

Routine monitoring of serum creatinine and MTX is being done for management of MTX-induced renal dysfunction (Grönroos et al., 2006). It is believed that the nephrotoxicity of MTX is mediated via the precipitation of MTX, renal dysfunction (Izzedine et al., 2005). and its metabolites in the renal tubules (Jacobs et al., 1976). or by a direct toxic effect of MTX on the renal tubules (Messmann et al., 2001). High doses of MTX can cause acute renal failure and elevation of serum urea, creatinine levels, uremia, and hematuria (Kintzel 2001).
The present study focused on oxidative stress in order to understand the mechanism of MTX-induced renal damage. Increase in lipid peroxidation, protein carbonyl content as well as markers of oxidative damage to the lipids and proteins was observed in the kidneys of MTX-treated rats by previous studies, and demonstrated increased oxidative stress in the kidneys of MTX-treated rats (Devrim et al., 2005). In the present investigation, significant reduction in kidney function was observed in animals treated with CURNPs plus CDDP and CURNPs plus MTX when compared with the CDDP and MTX groups, respectively. CURNPs significantly and dose-dependently improved urea and creatinine, and decreasing the elevated levels of serum urea and creatinine provides convincing evidence for participation of reactive oxygen species (ROS) in CDDP induced renal dysfunction. It may also be possible that CUR, due to its potential antioxidant properties, improves renal function via attenuating the oxidative stress (Sumanont et al., 2004).

\section{Effect of CURNPs on SOD and CAT}

The activities of SOD and CAT in the group treated with CDDP (PC1), MTX (PC2), CURNPs $(60,30 \mathrm{mg} / \mathrm{kg}$ b.w $)+$ CDDP/ MTX are given in Table 2. Renal SOD and CAT activities in the PC1 and PC2 were found to be decreased significantly $(p<0.05)$ when compared to the NC. Treatments of CURNPs $(60,30 \mathrm{mg} /$ kg b.w) + CDDP/ MTX effectively prevented the CDDP and MTX induced decline of SOD and CAT activities. On the other hand, activity of SOD and CAT in groups administration of CURNPs (60, $30 \mathrm{mg} / \mathrm{kg} \mathrm{b.w})$ significantly $(p<0.05)$ increased compared to the NC. Groups administration of CURNPs $(60 \mathrm{mg} / \mathrm{kg}$ b.w) gave the best results in SOD and CAT activities compared to the CURNPs (30 mg/kg b.w) and NC. 
In the present study, CAT and SOD are found to decrease after CDDP administration. This resulted in the decreased ability of the kidney to scavenge toxic hydrogen peroxide and lipid peroxides. Similar study demonstrated that CDDP administration caused marked deterioration of the endogenous antioxidant profile, as evidenced by decreased SOD and CAT activities (Kuhad et al., 2006). It has been observed that CDDP may initially reduce the levels and availability of endogenous oxygen radical scavengers such as SOD (Davis et al.,
2001). A plausible switch in the case of cisplatin is adenosine-tri-phosphate. The cells in this case lack energy and stop synthesizing significant amount of glutathione. As a result, mitochondrial lipid peroxidation, impairment of adenosine-triphosphatase (ATPase) activity, damage of mitochondrial DNA and disruption of intracellular calcium homeostasis have been reported (Zicca et al., 2002).

Table 2. Effect of CUR ( $30,60 \mathrm{mg} / \mathrm{kg} \mathrm{b.w)} \mathrm{and} \mathrm{CURNPs} \mathrm{(60,}$ $30 \mathrm{mg} / \mathrm{kg} \mathrm{b.w)}$ on serum SOD and CAT activities in male rats treated with Cisplatin ( $6 \mathrm{mg} / \mathrm{kg} \mathrm{b.w)}$ and Methotrexate $(20 \mathrm{mg} / \mathrm{kg} \mathrm{b.w})$.

\begin{tabular}{|ccc|}
\hline Treatments & SOD & Creatinine(mg/dI) \\
\hline$(\mathrm{U} / \mathrm{ml})$ & CAT & $0.01 \pm 0.74$ \\
\hline$(\mathrm{nmol} / \mathrm{min} / \mathrm{ml})$ & $22.72 \pm 0.65$ & $0.71 \pm 0.01$ \\
\hline Negative control NC & $0.39 \pm 24.37$ & $0.05 \pm 13.22$ \\
\hline CURNPs 60mg & $65.07 \pm 0.04$ & $35.92 \pm 0.42$ \\
\hline CURNPs 60mg + CDDP & $0.21 \pm 22.40$ & $0.51 \pm 13.88$ \\
\hline CURNPs 60mg + MTX & $23.55 \pm 0.16$ & $12.94 \pm 0.04$ \\
\hline CURNPs 30mg & $0.05 \pm 43.08$ & $0.06 \pm 24.93$ \\
\hline
\end{tabular}

Each value represents mean $\pm S D$ of six animals, CURNPs = curcumin nanoparticles, CDDP $(P C 1)=$ cisplatin (positive control 1), MTX (PC2) = Methotrexate (positive control 2), statistically significant at $P<0.05$ as compared to negative control (NC) (One-way ANOVA followed by Fischer's LSD test). 
In our study, CAT and SOD activities are found to decrease after MTX administration. MTX leads to a reduction in antioxidant enzymatic defense capacity and causes lipid peroxidation in renal tissue. The endogenous antioxidant enzymes are likely to be perturbed because of over-production of oxygen radicals, inactivation of detoxification systems, consumption of antioxidants, and failure to adequately replenish antioxidants in tissue (Öktem et al., 2006). The reduction in GSH levels promoted by methotrexate leads to a reduction in the effectiveness of the antioxidant enzyme defense system, sensitizing the cells to ROS (Lee et al., 2002). Thus, decreased NADPH and GSH levels cause a decrease in antioxidant enzyme defense system activities, which leads to possible oxidative renal stress. It has been proposed that antioxidants maintain the concentration of reduced GSH and may restore the cellular defense mechanisms and block lipid peroxidation, thus protecting against the toxicity of a wide variety of nephrotoxic chemicals (Gurer and Ercal 2000).

In addition, the results of the present study show that CURNPs attenuates the levels of SOD and CAT, thus provide convincing evidence that CURNPs significantly and dose-dependently ameliorated renal oxidative and nitrosative stress via scavenging ROS. This could be attributed to the high solubility of CURNPs increases its bioavailability and clinical efficacy. Engineered NPs possess greater surface to volume ratio and functionalities on their surfaces which could result in greater biological activity if these are taken into the body, making them a potential health concern (Rajendra et al., 2010). Also, significant increase in antioxidant enzymes activities was observed in animals treated with CURNPs + CDDP/ MTX when compared with the CDDP and MTX groups, respectively. We suggest that the ac tivities of antioxidant enzymes was modulated or reversed towards normal level by CUR pretreatment. It has been reported CUR-induced inhibition of cellular ROS generation (Balasubramanyam et al., 2003) and inhibited hydrogen peroxide induced cell damage. Also, CUR manganese complex and acetylcurcumin manganese complex showed much greater SOD activity and an inhibitory effect on lipid peroxidation (Davis et al., 2001). It has been shown that the origin of the antioxidant activity of CUR is mainly from the phenolic $\mathrm{OH}$ group, although a small fraction may be due to the $>\mathrm{CH} 2$ site (Baek et al., 2003; Kuhad et al., 2006). Our results suggest that the protective effect of CURNPs determined in our study may be mediated by similar mechanisms, thereby ameliorating CDDP and MTX-induced oxidative stress, which in turn results in protection against mitochondrial dysfunction produced by the drug.

\section{Effect of CURNPs on F2-isoprostanes}

The activity of F2-IsoPs were given in Table 3. The activity of F2-IsoPs were increased significantly $(p<0.05)$ in PC1 and PC2 compared to NC. Administration of CURNPs $(60,30 \mathrm{mg} / \mathrm{kg} \mathrm{b.w})$ + CDDP were decreased significantly $(p<0.05)$ compared to $P C 1$. It was observed $(0.28 \mathrm{ng} / \mathrm{ml}, 0.32 \mathrm{ng} / \mathrm{ml}$ and $0.45 \mathrm{ng} / \mathrm{ml}$ ) in groups administration of CURNPs (60 and $30 \mathrm{mg} / \mathrm{kg} \mathrm{b.w)} \mathrm{+}$ CDDP and PC1, respectively. Administration of CURNPs $(60,30 \mathrm{mg} / \mathrm{kg} \mathrm{b.w})$ + MTX were decreased significantly $(p<0.05)$ compared to PC2. It was observed $(0.27 \mathrm{ng} / \mathrm{ml}, 0.30 \mathrm{ng} / \mathrm{ml}$ and $0.53 \mathrm{ng} / \mathrm{ml}$ ) in groups administration of CURNPs (60 and 30mg/kg b.w) + MTX and $\mathrm{PC2}$, respectively. 
Table 3. Effect of CURNPs $(30,60 \mathrm{mg} / \mathrm{kg} \mathrm{b.w)} \mathrm{on} \mathrm{serum}$ $F-2$ Isoprostanes concentration in male rats treated with Cisplatin (6 mg/kg b.w) and Methotrexate (20 $m g / k g$ b.w).

\begin{tabular}{cc|}
\hline Treatments & F-2Isoprostanes \\
\hline$(\mathrm{ng} / \mathrm{ml})$ & CAT \\
\hline Negative control NC & $0.27 \pm 0.0008$ \\
\hline CURNPs 60mg & $0.0005 \pm 0.27$ \\
\hline CURNPs 60mg + CDDP & $0.28 \pm 0.0000$ \\
\hline CURNPs 60mg + MTX & $0.00 \pm 0.27$ \\
\hline CURNPs 30mg & $0.27 \pm 0.0005$ \\
\hline CURNPs 30mg + CDDP & $0.0005 \pm 0.32$ \\
\hline CURNPs 30mg + MTX & $0.30 \pm 0.00$ \\
\hline
\end{tabular}

Each value represents mean $\pm S D$ of six animals, CURNPS = curcumin nanoparticles, CDDP $(P C 1)=$ cisplatin (positive control 1), MTX (PC2) = Methotrexate (positive control 2), statistically significant at $P<0.05$ as compared to negative control (NC) (One-way ANOVA followed by Fischer's LSD test). 
As a marker of oxidative stress, we evaluated F2-IsoPs in serum. It is a biologically active F2-IsoPs known to be a reliable biomarker of lipid peroxidation (Cracowski et al., 2002). In the present study, CDDP and MTX treatment resulted in significant increases in the F2-IsoPs production. Previous study have been reported that depletion of renal GSH, which is one the primary reasons for the resulting lipid peroxidation, may cause increases in F2-IsoPs levels (Roberts et al., 2000). As with the current findings, our data indicates that the generation of free radicals and subsequent lipid peroxidation may play a role in cisplatin and methotrexate nephrotoxicity (Abraham et al., 2010). It is well documented that CDDP causes lipid peroxidation and in the kidneys via ROS generation (Matsushima et al., 1998). Other studies have been reported that oxidative stress and lipid peroxidation play an important role in the methotrexate-induced nephrotoxicity (Öktem et al., 2006; Abraham et al., 2010).

In this study, significant reduction in lipid peroxidation was observed in animals treated with CURNPs + CDDP/ MTX when compared to the PC1 and PC2. CURNPs significantly and dose-dependently attenuated lipid peroxidation in CDDP and MTX treated rats, providing convincing evidence for the involvement of ROS in CDDP and MTXinduced lipid peroxidation. It has been reported that a protective effect of CUR on circulating lipids and lipid peroxidation (Rukkumani et al., 2003). CUR attenuates oxidative DNA damage in the mouse epidermis (Shih and Lin 1993), and in cultured mouse fibroblast cells (Davis et al., 2001). These data are in agreement with previous studies done by various antioxidant supplementation (Al-Majed et al., 2003; Shimeda et al., 2005; Atessahin et al., 2005). The results of this study confirm that the consumption of CURNPs improves the status of oxidative stress agents in the serum and tissue.

\section{Effect of CURNPs on CDDP and MTX-induced changes in renal morphology}

Histopathologic changes of the Kidneys are shown in (Fig. 4). In the control group, renal tissue sections had a proximal convoluted tubules linning with cuboidal epithelial cells and distal convoluted tubules. The glomerulus surrounded with renal space and Bowman's capsule. Histologic examination of the kidneys exposed to CDDP (6 $\mathrm{mg} / \mathrm{kg} \mathrm{b.w)} \mathrm{showed} \mathrm{shrinkage} \mathrm{of} \mathrm{the}$ glomerulus with widening of the renal space. Degeneration and necrosis of the proximal convoluted tubules containing an excessive amount of cast deposition. Treatment with CURNPs $(60,30 \mathrm{mg} / \mathrm{kg}$ b.w) resulted in normal architecture of the distal and proximal convoluted tubules. Experimental evidence has suggested that the renal sections showed severe tubular necrosis, tubular atrophy, interstitial nephritis, and hyaline casts. It has been suggested that ROS may lead to tubular damage in CDDP-treated rats (Baliga et al., 1997; Kuhad et al., 2006). Treatment with CUR resulted in a marked morphological protection (Kuhad et al., 2007). In other study, extensive renal tubular injury was observed in the CDDP group $72 \mathrm{~h}$ after CDDP injection, including tubular cell necrosis, loss of brush border membrane and tubular dilatation. In contrast, the mice treated with CUR showed no obvious necrotic changes in the kidney (Ueki et al., 2013). 
Figure 4. Effects of CURNPs $(30,60 \mathrm{mg} / \mathrm{kg} \mathrm{b.w)} \mathrm{administration} \mathrm{on} \mathrm{renal} \mathrm{tissue,}$ photomicrographs of sections from renal cortex of various groups of male rats $(A-$ $I)$. (A) Control: rats received on equivalent volume of saline. (B) CURNPS: rats received CURNPs (60 $\mathrm{mg} / \mathrm{kg}$ b.w) showing normal appearance and structure of the renal corpuscles. (C) CDDP + CURNPs: rats received CDDP + CURNPs (60 mg/ $\mathrm{kg}$ b.w) showing a typical control architecture of the renal cortex. (D) MTX + CURNPS: rats received MTX + CURNPs (60 mg/kg b.w) showing congestion of the glomerular blood capillaries and some sites displayed congested and bleeded blood vessels, also, Well developed renal tubules were clearly noticed. (E) CURNPs: rats received CURNPs (30 mg/kg b.w) showing normal architecture of the distal and proximal convoluted tubules. (F) CDDP + CURNPs: rats received CDDP + CURNPS (30 mg/kg b.w) showing more or less normal renal tubules. (G) MTX + CURNPs: rats received MTX + CURNPs (30 mg/kg b.w) showing distinct improvement in the histological architecture of the renal cortex which revealed slight swollen glomerulus and organized distal and proximal convoluted tubules. (H) CDDP: rats received a single dose of Cisplatin (6 mg/kg b.w) showing slight shrinkage of the glomerulus with widening of the renal space, Degeneration and necrosis of the proximal convoluted tubules containing an excessive amount of cast deposition. (I) MTX: rats received a single dose of Methotrexate (20 mg/ $\mathrm{kg} \mathrm{b.w)} \mathrm{showing} \mathrm{shrinkage} \mathrm{of} \mathrm{the}$ renal corpuscle (glomerulus) with condensation of the glomerular capillary tuft and dilation of the capsular space. Also, sever necrosis and degeneration of the proximal convoluted tubules, both proximal and distal tubules contain detached epithelial cells. $(x=40 H \& E)$.
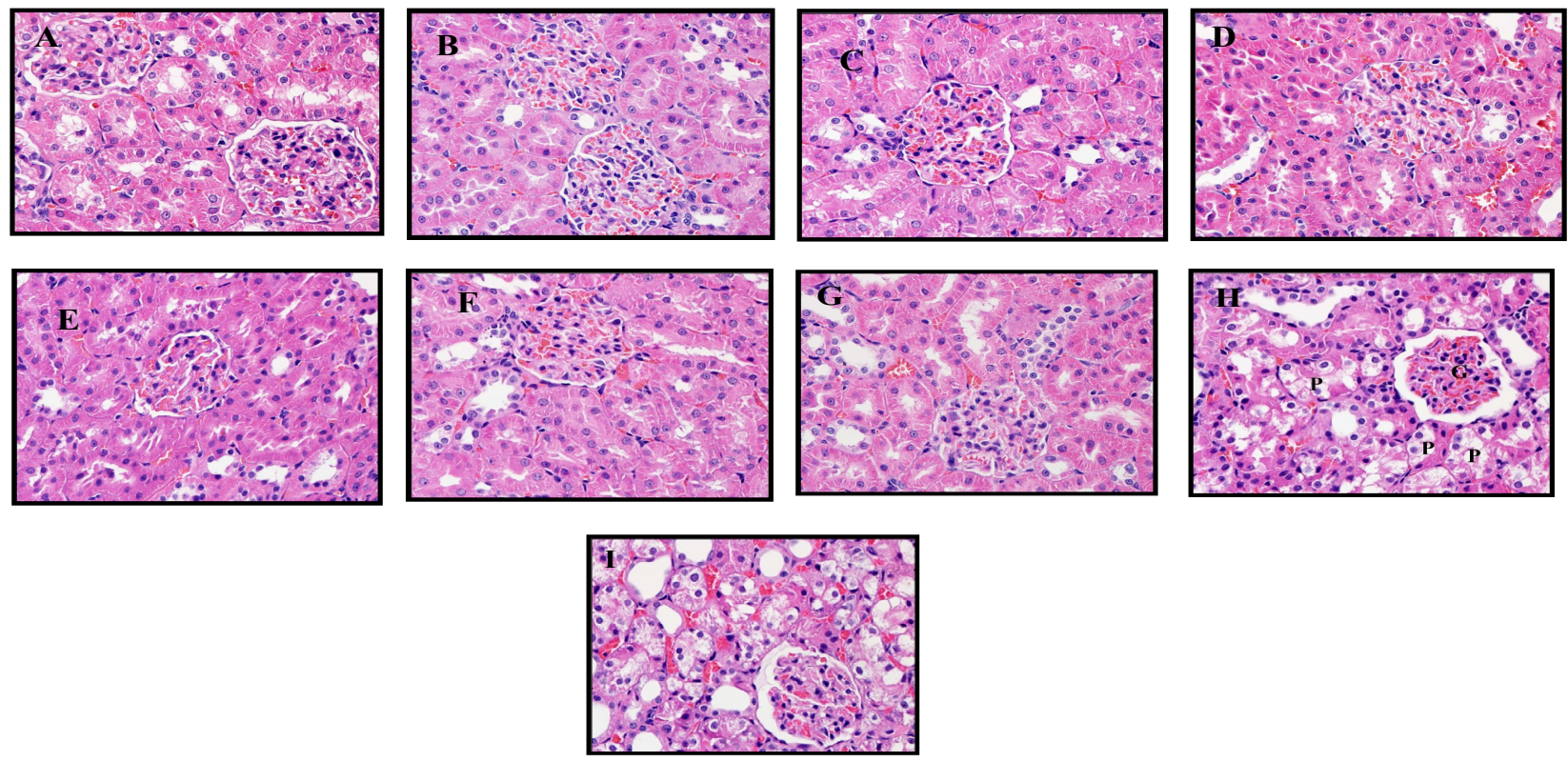
As seen in (Fig. 4), histologic examination of the kidneys exposed to MTX (20 $\mathrm{mg} / \mathrm{kg} \mathrm{b.w)} \mathrm{showed} \mathrm{shrinkage} \mathrm{of} \mathrm{the}$ renal corpuscle (glomerulus) with condensation of the glomerular capillary tuft and dilation of the capsular space. Also, sever necrosis and degeneration of the proximal convoluted tubules, both proximal and distal tubules contain detached epithelial cells. Treatment with CURNPs $(60,30 \mathrm{mg} / \mathrm{kg}$ b.w) resulted in a marked morphological protection. In MTX-induced renal damage, it can be assumed that a direct damage to the glomeruli, tubular obstruction or direct tubular toxicity, are further nephrotoxic mechanisms (Hempel et al., 2003). Our data corporates with other study which indicates that the generation of free radicals and subsequent lipid peroxidation may play a role in MTX nephrotoxicity (Öktem et al., 2006). It has been reported that the kidneys of MTX-treated rats results in severe glomerular and tubular nephritis. The glomeruli are necrotized and is infiltrated with fibrous tissue (Abraham et al., 2010). In another study we have demonstrated that treatment with MTX shows cell swelling and necrosis in renal tubular cells (Grönroos et al., 2006). In our study, Pretreatment with CURNPs before the administration of MTX reduced MTX induced damage to the kidneys. Besides, CURNPs restored the function of the kidney as shown by near normal serum urea and creatinine values. Similar effects of CUR were also reported in many conditions such as renal ischemia/ reperfusion injury (Bayrak et al., 2008). It may be possible that CUR, due to its potential antioxidant properties, improves renal function via attenuating oxidative stress mediated decline in renal hemodynamics (Sumanont et al., 2004). CURNPs prevented these CDDP and MTX-induced structural changes, suggesting possible involvement of ROS in mediating these histological alterations. We propose that CURNPs acts in the kidney as a potent scavenger of free radicals to prevent the nephrotoxicity effects of CDDP and MTX. 


\section{Conclusions}

CDDP and MTX-induced nephrotoxicity were confirmed by our study. CURNPs $(60,30 \mathrm{mg} / \mathrm{kg}$ b.w) had effect on the biochemical factors (urea and creatinine) and antioxidants enzymes (SOD and CAT) and F2-IsoPs. Also, histopathological properties of kidney tissue that were studied, had preventive by CURNPs (60,30mg/kg b.w). Our result clearly indicated the renoprotective potential of CURNPs $(60,30 \mathrm{mg} / \mathrm{kg} \mathrm{b.w})$ against CDDP and MTX -induced renal dysfunction in rats. Therefore, CURNPs has proved to be an effective free radical quencher. In addition, CURNPs formulation approach resulted in improved oral bioavailability, enhanced efficacy. Though further studies on quantitating bioavailability remains to be done CURNPs in oral route might be a promising antioxidant alternative to prevent kidney. 


\section{Acknowledgment}

This paper contains the results and fundings of a research project that is funded by King Abdulaziz City for Science and Technology (KACST) Grant No (P-S-12-0679). We gratefully acknowledge the assistance of the animal house in University of Dammam. 


\section{References}

Abelson, H. T., Fosburg, M. T. and Beardsley, G. P. (1983). "Methotrexate-induced renal impairment: clinical studies and rescue from systemic toxicity with high-dose leucovorin and thymidine", J Clin Oncol, Vol.1, pp. 208-216.

Abraham, P., Kolli, V. K. and Rabi, S. (2010). "Melatonin Attenuates Methotrexate-induced Oxidative Stress and Renal Damage in Rats", Cell Biochemistry and Function, Vol. 28, pp. 426-33.

Al-Majed, A. A., Abd-Allah, A. R., Al-Rikabi, A. C., Al-Shabanah, O. A. and Mostafa, A. M. (2003). "Effect of Oral Administration of Arabic Gum on Cisplatin-induced Nephrotoxicity in Rats", Journal of Biochemical and Molecular Toxicology, Vol, 17 pp. 146-53.

Appenroth, D., Fröb, S., Kersten, L., Splinter, F. K. and Winnefeld, K. (1997). "Protective Effects of Vitamin $E$ and $C$ on Cisplatin Nephrotoxicity in Developing Rats", Archives of Toxicology, Vol. 71, pp. 677-83.

Atessahin, A., Yilmaz, S., Karahan, I., Ceribasi, A. O. and Karaoglu, A. (2005). "Effects of Lycopene against Cisplatin-induced Nephrotoxicity and Oxidative Stress in Rats", Toxicology, Vol. 212, pp. 116-23.

Baek, S. M., Kwon, C. H., Kim, J. H., Woo, J. S., Jung, J. S. and Kim, Y. K. (2003) "Differential Roles of Hydrogen Peroxide and Hydroxyl Radical in Cisplatin-induced Cell Death in Renal Proximal Tubular Epithelial Cells", Journal of Laboratory and Clinical Medicine, Vol. 142, pp. 178-86.
Balasubramanyam, M., Koteswari, A. A., Kumar, R. S., Monickaraj, S. F., Maheswari, J. U. and Mohan, V. (2003). "Curcumin-induced Inhibition of Cellular Reactive Oxygen Species Generation: Novel Therapeutic Implications", Journal of Biosciences, Vol. 28, pp. 715-21.

Baliga, R., Ueda, N., Walker, P. D. and Shah, S. V. (1997). "Oxidant Mechanisms in Toxic Acute Renal Failure", American Journal of Kidney Diseases, Vol. 29, pp. 465-77.

Barthes, H., Bohemer, M., and Heirli, C. (1972). "Colorimetric kinetic method of creatinine", Clin Chem Acta, Vol. 37, pp. 193.

Bayrak, O., Uz, E., Bayrak, R., Turgut, F., Atmaca, A. F., Sahin, S., Yıldırım, M. E., Kaya, A., Cimentepe, E. and Akcay, A. (2008). "Curcumin Protects against Ischemia/reperfusion Injury in Rat Kidneys", World Journal of Urology, Vol. 26, pp. 285-91.

Cohly, H. H., Taylor, A., Angel, M. F. and Salahudeen, A. K. (1998). "Effect of Turmeric, Turmerin and Curcumin on H2O2-Induced Renal Epithelial (LLC-PK1) Cell Injury", Free Radical Biology and Medicine, Vol. 24, pp. 49-54.

Cracowski, J., Durand, T. and Bessard, G. (2002). "Isoprostanes as a Biomarker of Lipid Peroxidation in Humans: Physiology, Pharmacology and Clinical Implications", Trends in Pharmacological Sciences, Vol. 23, pp. 360-66. 
Das, K. C., and Das, C. K. (2002). "Curcumin (diferuloylmethane), a Singlet Oxygen Quencher", Biochemical and Biophysical Research Communications, Vol. 29, pp. 62-66.

Davis, C. A., Nick, H. S. and Agarwal, A. (2001). "Manganese superoxide dismutase attenuates cisplatin-induced renal injury: importance of superoxide", J Am Soc Nephrol, Vol. 12, pp. 2683-2690.

Devadasu, V. R., Wadsworth, R. M. and Ravi Kumar, M. N. V. (2011). "Protective Effects of Nanoparticulate Coenzyme Q10 and Curcumin on Inflammatory Markers and Lipid Metabolism in Streptozotocin-induced Diabetic Rats: A Possible Remedy to Diabetic Complications", Drug Delivery and Translational Research, Vol. 1, pp. 44855.

Devrim, E., Çetin, R., Kılıçoğlu, B., Ergüder, B. I., Avcı, A. and Durak, I. (2005). "Methotrexate Causes Oxidative Stress in Rat Kidney Tissues", Renal Failure, Vol. 27, pp. 771-73.

Durak, I., Özbek, H., Karaayvaz, M. and Öztürk, H. S. (2002). "Cisplatin Induces Acute Renal Failure By Impairing Antioxidant System In Guinea Pigs: Effects Of Antioxidant Supplementation On The Cisplatin Nephrotoxicity", Drug and Chemical Toxicology, Vol. 25, pp. 1-8.

Fabbro, E. D., Dalal, S. and Bruera, E. (2006). "Symptom Control in Palliative Care-Part II: Cachexia/Anorexia and Fatigue", Journal of Palliative Medicine, Vol. 9, pp. 409-21.

Fam, S. S. and Morrow, J. D. (2003) ."The Isoprostanes: Unique Products of Arachidonic Acid Oxidation-A Review", Current Medicinal Chemistry, Vol. 10, pp. 1723-740.
Fawcett, J. K. and Soctt, J. E. (1960). "Enzymatic colorimetric method of urea", J Cline Path, Vol. 13, pp. 156.

Feczkó, T., Tóth, J. and Gyenis, J. (2008). "Comparison of the Preparation of PLGA-BSA Nano- and Microparticles by PVA, Poloxamer and PVP", Colloids and Surfaces A: Physicochemical and Engineering Aspects, Vol. 319, pp. 188-95.

Grönroos, M., Chen, M., Jahnukainen, T., Capitanio, A., Aizman, R. I. and Celsi, G. (2006). "Methotrexate Induces Cell Swelling and Necrosis in Renal Tubular Cells", Pediatric Blood \& Cancer, Vol. 46, pp. 624-29.

Grosso, S., Longini, M., Rodriguez, A., Proietti, F., Piccini, B., Balestri, P. and Buonocore, G. (2011). "Oxidative Stress in Children Affected by Epileptic Encephalopathies", Journal of the Neurological Sciences, Vol. 300, pp. 103-06.

Gurer, H., and Ercal, N. (2000). "Can Antioxidants Be Beneficial in the Treatment of Lead Poisoning?" Free Radical Biology and Medicine, Vol. 29, pp. 927-45.

Hannemann, J., and Baumann, K. (1988). "Cisplatin-induced Lipid Peroxidation and Decrease of Gluconeogenesis in Rat Kidney Cortex: Different Effects of Antioxidants and Radical Scavengers", Toxicology, Vol. 51, pp. 119-32.

Hempel, L., Misselwitz, J., Fleck, C., Kentouche, K., Leder, C., Appenroth, D., Rost, M. and Zintl, F. (2003). "Influence of High-dose Methotrexate Therapy (HD-MTX) on Glomerular and Tubular Kidney Function", Medical and Pediatric Oncology, Vol. 40, pp. 348-54. 
Hsu, P. C., Lan, J. L., Hsieh, T. Y., Jan, Y. J. and Huang, W. N. (2003). "Methotrexate pneumonitis in a patient with rheumatoid arthritis", J Microbiol Immunol Infect, Vol. 36, pp. 137-140.

Il'Yasova, D., Kennedy, K., Spasojevic, I., Wang, F., Tolun, A. A., Base, K., Young, S. P., Marcom, P. K., Marks, J., Millington, D. S. and Dewhirst, M. W. (2011). "Individual Responses to Chemotherapy-induced Oxidative Stress", Breast Cancer Research and Treatment, Vol. 125, pp. 583-89.

Il'Yasova, D., Spasojevic, I., Wang, F., Tolun, A. A., Base, K., Young, S. P., Marcom, P. K., Marks, J., Mixon, G., Digiulio, R. and Millington, D. S. (2010). "Urinary Biomarkers of Oxidative Status in a Clinical Model of Oxidative Assault", Cancer Epidemiology Biomarkers \& Prevention, Vol. 19, pp. 1506-510.

Izzedine, H., Launay-Vacher, V., Karie, S., Caramella, C., Person, F. D. and Deray, G. (2005). "Is Lowdose Methotrexate Nephrotoxic? Case Report and Review of the Literature", Clinical Nephrology, Vol. 64, pp. 31519.

Jacobs, S. A., Stoller, R. G., Chabner, B. A. and Johns, D. G. (1976). "7-Hydroxymethotrexate as a Urinary Metabolite in Human Subjects and Rhesus Monkeys Receiving High Dose Methotrexate", Journal of Clinical Investigation, Vol. 57, pp. 534-38.

Jahovic, N., Çevik, H., Şehirli, A. Ö., Yeğen, B. Ç. and Şener, G. (2003). "Melatonin Prevents Methotrexate-induced Hepatorenal Oxidative Injury in Rats", Journal of Pineal Research, Vol. 34, pp. 282-87.
Jin-Gang, Z. and Lindup, W. (1993). "Role of Mitochondria in Cisplatin-induced Oxidative Damage Exhibited by Rat Renal Cortical Slices", Biochemical Pharmacology, Vol. 45, pp. 2215-222.

Kannan, K., and Jain, S. K. (2000). "Oxidative Stress and Apoptosis", Pathophysiology, Vol. 7, pp. 153-63.

Kersten, L., Br"aunlich, H., Keppler, B. K., Gliesing, C., Wendelin, M. and Westphal, J. (1998). "Comparative nephrotoxicity of some antitumoractive platinum and ruthenium complexes in rats", J Appl Toxicol, Vol. 18, pp. 93-101.

Kim, J. E., Kim, A. R., Chung, H. Y., Han, S. Y., Kim, B. S. and Choi, J. S. (2003). "In vitro peroxynitrite scavenging activity of diarylheptanoids from Curcuma longa", Phyto therapy Research, Vol. 17, pp. 481-484.

Kintzel, P. E. (2001). "Anticancer Drug???Induced Kidney Disorders", Drug Safety, Vol. 24, pp. 19-38.

Koyama, S., Sato, E., Takamizawa, A., Tsukadaira, A., Haniuda, M., Kurai, M., Numanami, H., Nagai, S. and Izumi, T. (2003). "Methotrexate Stimulates Lung Epithelial Cells To Release Inflammatory Cell Chemotactic Activities", Experimental Lung Research, Vol. 29, pp. 91-111.

Kuhad, A., Tirkey, N., Pilkhwal, S., and Chopra, K. (2006). "6-Gingerol Prevents Cisplatin-induced Acute Renal Failure in Rats", BioFactors, Vol. 26, pp. 189-200.

Kuhad, A., Pilkhwal, S., Sharma, S., Tirkey, N. and Chopra, K. (2007). "Effect of Curcumin on Inflammation and Oxidative Stress in Cisplatin-Induced Experimental Nephrotoxicity", Journal of Agricultural and Food Chemistry, Vol. 55, pp. 10150-0155. 
Lee, S. M., Koh, H., Park, D. C., Song, B. J., Huh, T. L. and Park, J. W. (2002). "Cytosolic NADP -dependent Isocitrate Dehydrogenase Status Modulates Oxidative Damage to Cells", Free Radical Biology and Medicine, Vol. 32, pp. 1185-196.

Luck, H. (1963). "Methods of Enzymatic Analysis. Verlag Chemie Academic Press", New York USA, pp. 885-888.

Matsushima, H., Yonemura, K., Ohishi, K. and Hishida, A. (1998). "The Role of Oxygen Free Radicals in Cisplatin-induced Acute Renal Failure in Rats", Journal of Laboratory and Clinical Medicine, Vol. 131, pp. 518-26.

Mcmanaman, J. L. (2002). "Structural and Conformational Analysis of the Oxidase to Dehydrogenase Conversion of Xanthine Oxidoreductase", Journal of Biological Chemistry, vol. 277, pp. 21261-1268.

Messmann, R. A. and Allegra, C. J., Antifolates; In: Chabner B. A. and Longo, D. L. (2001). (eds). "Cancer Chemotherapy and Biotherapy", Philadelphia, Lippincott Williams \& Wilkins, pp. 139-184.

Morrow, J. D. and Roberts, L. J. (1997). "The Isoprostanes: Unique Bioactive Products of Lipid Peroxidation", Progress in Lipid Research, Vol. 36, pp. 1-21.

Ohkuma, N., Matsuo, S., Tutsui, M. and Ohkawara, A. (1982). "Superoxide dismutase in the epidermis Q4 (author's transl) ", Nippon Hifuka Gakkai Zasshi, Vol. 92, pp. 583-590.

Öktem, F., Yilmaz, H. R., Ozguner, F., Olgar, S., Ayata, A., Uzar, E. and Uz, E. (2006). "Methotrexate-induced Renal Oxidative Stress in Rats: The Role of a Novel Antioxidant Caffeic Acid Phenethyl Ester", Toxicology and Industrial Health, Vol. 22, pp. 241-47.
Pabla, N. and Dong, Z. (2008). "Cisplatin Nephrotoxicity: Mechanisms and Renoprotective Strategies", Kidney International, Vol. 73, pp. 994-1007.

Panchal, H. D., Vranizan, K., Lee, C. Y., Ho, J., Ngai, J. and Timiras, P. S. (2008). "Early Anti-Oxidative and Anti-Proliferative Curcumin Effects on Neuroglioma Cells Suggest Therapeutic Targets", Neurochemical Research, Vol. 33, pp. 1701-710.

\section{Protas, P. T., Muszynska-Roslan, K., Holownia, A., Krawczuk-Rybak, M. and Braszko, J. J. (2010). "Ce-} rebrospinal fluid oxidative stress during chemotherapy of acute lymphoblastic leukemia in children", Pediatric Hematology-Oncology, Vol. 27, pp. 306-13.

\section{Rajendra, R., Balakumar, C.,} Ahammed, H., Jayakumar, S., Vaideki, K. and Rajesh, E. (2010). "Use of Zinc Oxide Nano Particles for Production of Antimicrobial Textiles", International Journal of Engineering, Science and Technology, Vol. 2, pp. 202-08.

\section{Roberts, L.J. and Jason, D.M.} (2000). "Measurement of F2-isoprostanes as an Index of Oxidative Stress in Vivo." Free Radical Biology and Medicine 28.4: 505-13.

Rukkumani, R. S., Balasubashini, M. and Menon, V. P. (2003). "Protective Effects of Curcumin and Photo-irradiated Curcumin on Circulatory Lipids and Lipid Peroxidation Products in Alcohol and Polyunsaturated Fatty Acid-induced Toxicity", Phytotherapy Research, Vol. 17, pp. 925-29.

Sadzuka, Y., Shoji, T. and Takino, Y. (1992). "Effect of Cisplatin on the Activities of Enzymes Which Protect against Lipid Peroxidation", Biochemical Pharmacology, Vol. 43, pp. 1872-875. 
Safirstein, R., Miller, P. and Guttenplan, J. B. (1984). "Uptake and Metabolism of Cisplatin by Rat Kidney", Kidney International, Vol. 25, pp. 75358.

Shi, A., Li, D., Wang, L., Li, B. and Adhikari, B. (2011). "Preparation of Starch-based Nanoparticles through High-pressure Homogenization and Miniemulsion Cross-linking: Influence of Various Process Parameters on Particle Size and Stability", Carbohydrate Polymers, Vol. 83, pp. 1604-610.

Shih, C. and Lin, J. (1993). "Inhibition of 8-hydroxydeoxyguanosine Formation by Curcumin in Mouse Fibroblast Cells", Carcinogenesis, Vol. 14, pp. 709-12.

Shimeda, Y., Hirotani, Y., Akimoto, Y., Shindou, K., Ijiri, Y., Nishihori, T. and Tanaka, K. (2005). "Protective Effects of Capsaicin against Cisplatin-Induced Nephrotoxicity in Rats." Biological \& Pharmaceutical Bulletin, Vol. 28, pp. 1635-638.

Sreejayan, and Rao, M. N. A. (1997). "Nitric Oxide Scavenging by Curcuminoids", Journal of Pharmacy and Pharmacology, Vol. 49, pp. 10507.

Sreejayan, N., Rao, M. N. A., Priyadarsini, K. I. and Devasagayam, T. P. A. (1997). "Inhibition of Radiation-induced Lipid Peroxidation by Curcumin", International Journal of Pharmaceutics, Vol. 151, pp. 127-30.

Srivastava, R. C., Farookh, A., Ahmad, N., Misra, M., Hasan, S. K. and Husain, M. M. (1996). "Evidence for the Involvement of Nitric Oxide in Cisplatin-induced Toxicity in Rats", Biometals, Vol. 9, pp. 139-142.
Sugihara, K. and Gemba, M. (1986). "Modification of Cisplatin Toxicity by Antioxidants", The Japanese Journal of Pharmacology, Vol. 40, pp. 353-55.

Sugihara, K., Nakano, S., Koda, M., Tanaka, K., Fukuishi, N. and Gemba, M. (1987). "Stimulatory Effect of Cisplatin on Production of Lipid Peroxidation in Renal Tissues", The Japanese Journal of Pharmacology, Vol. 43, pp. 247-52.

Sumanont, Y., Murakami, Y., Tohda, M., Vajragupta, O., Matsumoto, K. and Watanabe, H. (2004). "Evaluation of the Nitric Oxide Radical Scavenging Activity of Manganese Complexes of Curcumin and Its Derivative", Biological \& Pharmaceutical Bulletin, Vol. 27, pp. 170-73.

Tuba, A. K. and Gülçin, I. (2008). "Antioxidant and Radical Scavenging Properties of Curcumin", Chemico-Biological Interactions, Vol. 174, pp. 2737.

Turesson, C. and Matteson, E. L. (2006). "Genetics of Rheumatoid Arthritis", Mayo Clinic Proceedings, Vol. 81, pp. 94-101.

Ueki, M., Ueno, M., Morishita, J. and Maekawa, N. (2013). "Curcumin Ameliorates Cisplatin-induced Nephrotoxicity by Inhibiting Renal Inflammation in Mice", Journal of Bioscience and Bioengineering, Vol. 115, pp. 547-51.

Weijl, N. I., Hopman, G. D., Wipkink-Bakker, A., Lentjes, E. G., Berger, H. M., Cleton, F. J. and Osanto, S. (1998). "Cisplatin combination chemotherapy induces a fall in plasma antioxidants of cancer patients". Ann Oncol, Vol. 9, pp. 1331-7. 
Wu, K., Li, J., Wang, W. and

Winstead, D. A. (2009). "Formation and Characterization of Solid Dispersions of Piroxicam and Polyvinylpyrrolidone Using Spray Drying and Precipitation with Compressed Antisolvent", Journal of Pharmaceutical Sciences, Vol. 98, pp. 2422-431.

Yao, X., Panichpisal, K., Kurtzman, N. and Nugent, K. (2007). "Cisplatin Nephrotoxicity: A Review", The American Journal of the Medical Sciences, Vol. 334, pp. 115-24.

Ye, S. F., Hou, Z. Q., Zhong, L. M. and Zhang, Q. Q. (2007). "Effect of curcumin on the induction of glutathione S-transferases and NADP $(H)$ : quinone oxidoreductase and its possible mechanism of action", Yao Xue Xue Bao, Vol. 42, pp. 376-380.

Zicca, A., Cafaggi, S., Mariggiò, M. A., Vannozzi, M. O., Ottone, M., Bocchini, V., Caviglioli, G. and Viale, M. (2002). "Reduction of Cisplatin Hepatotoxicity by Procainamide Hydrochloride in Rats", European Journal of Pharmacology, Vol. 442, pp. 265-72. 


\section{About the authors}

Professor Soheir N. Abd El. Rahman is a Professor in the Crops Technology Research Department, Food Technology Research Institute, Agriculture Research Center, Giza, Egypt. She is working now in Univ. of Dammam - Science College. She received her PhD in 2000 from the Department of Biochemistry, Faculty of Agriculture, Cairo University, Egypt. Her research interests include chronic diseases, food technology and environmental biotechnology. Her specific focus is on natural resources for diabetic, cholesterolimia, fertility, oxidative stress and celiac diseases. She is also working on the natural additives of food, environmental protection, nanoparticles and recycling wastes to use in different industries and purification (oils, drinking water and wastewater).

Suhailah S. Al-Jameel is a Lecturer at the University of Dammam, Saudi Arabia. She received her Bachelor of Science degree in 2003 from the General Presidency for Female Education, Presidency Agency for Girls College, Girls College of Science, Dammam, Saudi Arabia. She received her master degree in 2008 from the College of Science, University of Dammam. Her research focus is biochemistry. 